\title{
Perspective: causes and functional significance of temporal variations in attention control
}

\author{
Agatha Lenartowicz $^{1 *}$, Gregory V. Simpson ${ }^{2}$ and Mark S. Cohen ${ }^{1}$ \\ Department of Psychiatry and Biobehavioral Sciences, Semel Institute for Neuroscience and Human Behavior, University of California Los Angeles, \\ Los Angeles, CA, USA \\ ${ }^{2}$ Attention Research Institute, San Francisco, CA, USA
}

Edited by:

Joy Geng, University of California

Davis, USA

Reviewed by:

R. Nathan Spreng, Cornell

University, USA

Francisco X. Castellanos, New York

University School of Medicine, USA

Jane Couperus, Hampshire College,

USA

\section{*Correspondence:}

Agatha Lenartowicz, Semel Institute

for Neuroscience and Human

Behavior, University of California Los

Angeles, 760 Westwood Plaza,

Suite 17-369, Los Angeles,

CA 90095, USA

e-mail: alenarto@ucla.edu
Attention control describes the human ability to selectively modulate the plethora of sensory signals and internal thoughts. The neural systems of attention control have been studied extensively, warranted by the importance of this ability to daily functioning. Here, we consider an emerging theme in the study of attention control-slow temporal fluctuations. We posit that these fluctuations are functionally significant, and may reflect underlying interactions between the neural systems related to attention control. We explore thought experiments to generate different perspectives on landscapes created by the interactions between attention control networks and the sources of input to these control systems. We examine interactions of the fronto-parietal and the default mode networks in the context of internal cognition, and the noradrenergic modulatory projections in the context of arousal, and we consider the implications of these inter-network dynamics on attention states and attention disorders. Through these thought experiments we highlight the breadth of potential knowledge to be gained from the study of slow fluctuations in attention control.

Keywords: attention control, fluctuations, network interactions, attention deficits, internal cognition

\section{ATTENTION CONTROL AND FLUCTUATIONS}

Attention control allows us to ignore distracting information so that we may focus selectively on information relevant to goal directed behavior. Copious research has demonstrated that attention control involves "top-down" signals from association cortices, biasing activity in sensory regions to enhance the magnitude of attended signals; and evidence is building to show that topdown processes also suppress the magnitude of ignored signals (Posner and Dehane, 1994; Desimone and Duncan, 1995; Miller and Cohen, 2001). Integral to top-down biasing is the frontoparietal network (FPN, also referred to as the "executive control network") (Corbetta and Shulman, 2002; Dosenbach et al., 2006; Fox et al., 2006; Raichle, 2011), a network encompassing dorsal and medial prefrontal cortices and superior parietal cortices, that acts to distinguish attended from ignored signals (Ruff and Driver, 2006; Gazzaley et al., 2007; Capotosto et al., 2009) (Figure 1A, left panel). Recruitment of this system is thought to occur when multiple sensory signals compete for processing resources (Braver and Cohen, 2000; Botvinick et al., 2001; Miller and Cohen, 2001) and/or at the trigger of a salient orienting signal (e.g., novel or loud sound, such as a fire alarm; Posner and Petersen, 1990; Posner and Dehane, 1994).

Attention control also appears to be a fluctuating system. Castellanos et al. (2005) showed that the speed of response in an attention task increases and decreases over a period of $15 \mathrm{~s}$ $(0.068 \mathrm{~Hz})$ or so, and that these fluctuations are particularly pronounced in children with attention deficit hyperactivity disorder (ADHD). Monto et al. (2008) showed that the accuracy in a simple detection task fluctuates in runs of $10-100 \mathrm{~s}$, that track electrophysiological fluctuations of the same period. The activity of the FPN also shows fluctuations in this frequency range (Vincent et al., 2008). These findings indicate that attention control integrity varies across time, and that this variability has implications for behavior and disease. In contrast, predominant models of attention are concerned with what we term "momentto-moment attention" (Figure 1A, right panel); they explain how attention control influences the processing of discrete, primarily external, sensory events by averaging attention signals across moments-and as such across fluctuations-in time. In the current perspective we therefore explore the emerging question, what are the causes and functional significance of temporal variations in attention control?

\section{SYSTEMIC AND INPUT SOURCES OF FLUCTUATIONS}

If we consider the FPN as a core system that underlies attention control, then fluctuations of attention control (proportional to the strength of modulation of the relative strengths of target and distractor signals, Figure 1A) likely indicate fluctuations in the efficacy of this system. Sources of these fluctuations may be classified further as either systemic or input. A systemicallybased fluctuation in efficacy would be defined as a limitation in FPN functionality occurring when the entire system is temporarily less active, either because of operational characteristics (e.g., the entire system is activated insufficiently) or because of negative interactions with other neural systems (e.g., its activity is suppressed by another system) - with no change to the inputs. An input-based fluctuation would be defined as a misdirection of FPN activity relative to a desired goal, such as when 


\section{A Attention Control Engagement}
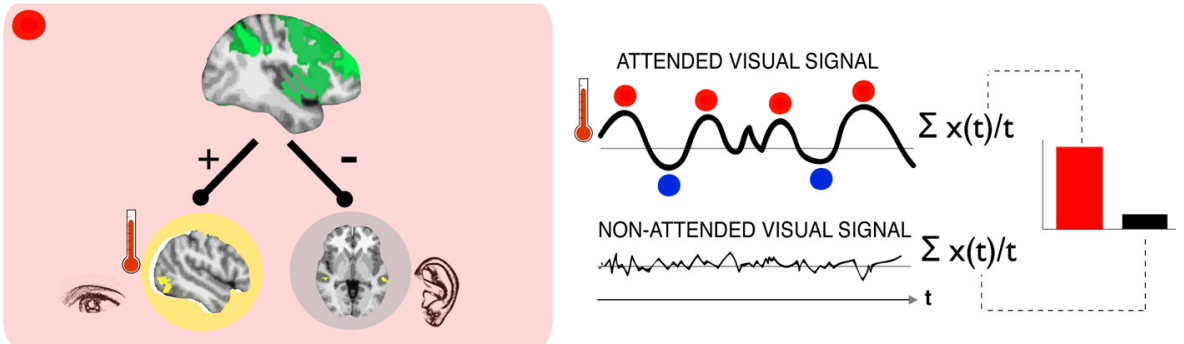

\section{B Sources of Fluctuation (๑)}

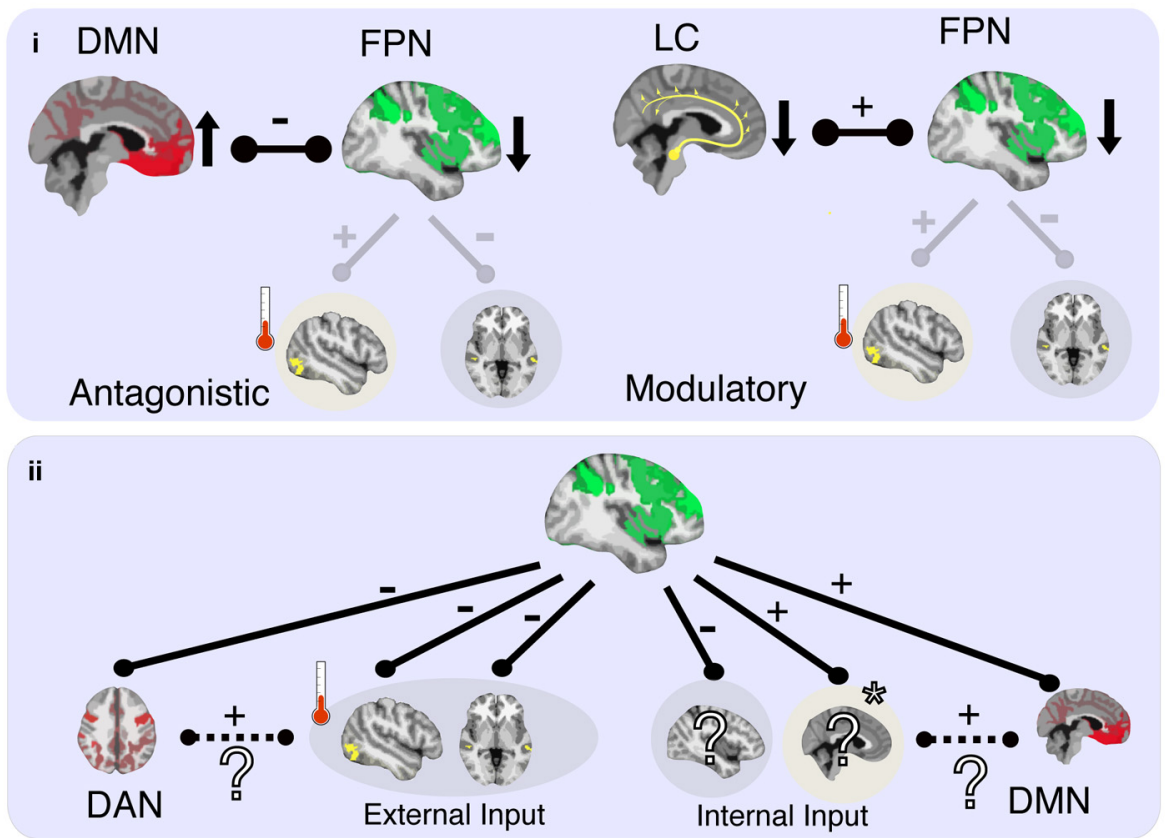

FIGURE 1 | In a representative scenario of attention control and its fluctuations (A), (left panel) activity corresponding to an attended signal (e.g., visual cortex) is enhanced (red thermometer level is high) and activity corresponding to an ignored signal (e.g., auditory) is suppressed, due to control signals from the FPN. The magnitude of enhancement is quantified by comparing activity for the target stimulus when it is attended relative to when it is ignored (right panel). This can be conceived as an average index of "moment-to-moment" attention, an approach that ignores any underlying fluctuations in the attended signal amplitude (blue and red dots) that may be related to functionally significant variations in attention control. Potential sources of such fluctuations are shown below (B), and can be system-based (i) and input-based (ii). In the case of systemic sources a decrease in FPN activity could arise by (i), the antagonistic influence of another network (left; DMN-default mode network) or decreased modulatory input (right; LC-locus coeruleus noradrenergic inputs) that decrease activity in FPN, leading to an attenuation of control over sensory processing regions, and therefore lower indices of control as measured in the target processing region (red thermometer level is (ow). In the case of input-based fluctuations, FPN activity level does not change but is redirected to a different processing input (ii). In this example attention is oriented toward an internal input (e.g., a memory, indicated by ${ }^{*}$ ), resulting in a decrease in responses to other inputs-including other internal inputs (e.g., planning dinner) and the external target (visual) inputs. The identity of cortical regions that process internal inputs is unknown (?), as are the interactions of such regions with higher-order networks (e.g., DAN/DMN). We posit here one possibility, that the input cortices and higher-order networks responsible for their processing will be positively correlated in their relationship with FPN. In the example here, the involuntary capture of attention by an internal input leads to positive correlations between DMN and FPN. attention control is rerouted by distracting signals, be they external signals or, as we consider here, internal thoughts-without a change in FPN activation. Therefore, a key to understanding the fluctuations in efficacy of attention control is knowledge of the conditions for, and products of, the interactions of FPN with other neural systems and inputs. We consider here two such candidates, arousal and internal cognition.

\section{THE CASE OF AROUSAL}

The idea of a systemic fluctuation of FPN is demonstrated readily in the effect that chemical neuromodulators have on its efficacy. All four of the primary neuromodulators, the catecholamines (dopamine and noradrenaline), acetylcholine and serotonin, have been shown to affect attention (Foote and Morrison, 1987; Coull, 1998; Briand et al., 2007; Rokem et al., 2010). For brevity we 
focus on the example of the noradrenergic (NE) system (for a comprehensive review see Moore and Bloom, 1979; Foote et al., 1983; Berridge and Waterhouse, 2003), often referred to as the LC-NE system because all of its cortical projections arise from a single nucleus in the brainstem, the locus coeruleus (LC). The LC-NE system is of interest because, being part of the reticular activating system (Moruzzi and Magoun, 1949), historically it has been associated with arousal (Berridge and Waterhouse, 2003). In turn, arousal is a prerequisite for attention. Indeed decreased firing of LC neurons is correlated both with drowsiness (Roussel et al., 1967; Aston-Jones and Bloom, 1981) and with poor attentional performance (Mason and Iversen, 1978; Aston-Jones et al., 1999). Excess LC firing, like excess arousal, is also detrimental to performance (Aston-Jones et al., 1999).

How do these observations contribute to systemic fluctuations of FPN? The LC-NE system has diffuse projections across cortex, with terminals that include the FPN (Moore and Bloom, 1979). The effect of NE, specifically, is to decrease spontaneous firing and increase the evoked response (Foote et al., 1975), interpreted as an increase in fidelity and gain of the neuronal response (AstonJones and Cohen, 2005). The LC-NE system therefore influences the responsivity of FPN to inputs (as well as of other systems) when attention control is required. This suggests that the LC-NE system could contribute to fluctuations of attention control when the LC-NE system is either under- or overactive, translating into a weaker or stronger response of the FPN as an entire system, given no change in the inputs (Aston-Jones and Cohen, 2005; for a complementary interpretation see Corbetta and Shulman, 2002; Corbetta et al., 2008). This is therefore a systemic not an input fluctuation of attention control. A weaker response of the FPN would translate into weaker modulatory control over target regions, meaning less target enhancement and less distractor suppression (Figure 1B-i, right panel).

\section{THE CASE OF INTERNAL COGNITION}

A very different example of a seemingly systemic fluctuation is internal cognition, which refers to thinking; it encompasses mind wandering, self-evaluation, problem solving and active remembering (Giambra, 1995; Smallwood and Schooler, 2006; McVay and Kane, 2009, 2010; Schooler et al., 2011; Christoff, 2012; Smallwood, 2012), processes that have been associated with the activation of a group of functionally connected regions that include medial prefrontal cortex, posterior cingulate cortex, restrosplenial cortex, as well as medial temporal and lateral inferior parietal cortices (Binder et al., 1999; Gusnard et al., 2001; Johnson et al., 2002; Gordon et al., 2007; Mason et al., 2007; Buckner et al., 2008; Christoff et al., 2009; Andrews-Hanna et al., 2010; Stawarczyk et al., 2011). Together these regions comprise the so-called default mode network (DMN) (Shulman et al., 1997; Mazoyer et al., 2001; Raichle et al., 2001; Buckner et al., 2008).

Internal cognition is of particular interest because thinking can, in principle, interfere with attention control over external inputs both through systemic and input pathways. As a systemic influence thinking can be considered a competitor to FPN activity (Figure 1B-i, left panel). This hypothesis is supported by early findings showing that FPN activity is correlated negatively with that of the DMN (Fox et al., 2005; Fox and Raichle,
2007). In turn, DMN activity is correlated positively with lapses of external attention (Weissman et al., 2006), reflecting moments when participants are off-task (Buckner et al., 2008; AndrewsHanna, 2012) and have decreased control over external signals (Weissman et al., 2009; Schooler et al., 2011; Smallwood et al., 2012). Accordingly, fluctuations of attention control could be interpreted as instances during which DMN activation suppresses activity in the FPN and attention control is disrupted by internal cognition, a systemic fluctuation of attention in reference to external signals.

A model based on antagonistic interaction between FPN and DMN, while a useful starting point, is likely an oversimplification of the underlying dynamics. It assumes that internal control and external control are independent, antagonistic systems, which leads to the difficult question: "Who" determines which type of control is "on" at any given time? Plausibly, the FPN and DMN interact within a negative feedback circuit (where each suppresses the other), and their individual engagement is determined by the strength of their relative inputs. This does not seem consistent with our ability to quickly switch between internal and external cognition - with no change in inputs. Alternatively, some other system determines whether external attention control or internal cognition is engaged (Sridharan et al., 2008; Leech et al., 2012). A more parsimonious interpretation is that FPN is that other system. Namely, DMN activity can be thought of as another input into FPN that is suppressed when attention is oriented externally-resulting in an apparent negative correlation between the two systems. The activation of DMN while attempting to attend to external signals would then be thought of as an input-based source of fluctuation (Figure 1B-ii).

Perhaps most telling with regard to this notion is the observation that in some circumstances the DMN and FPN are correlated positively (Christoff et al., 2009; Spreng et al., 2010; Smallwood et al., 2012; Spreng et al., 2013), arguing against a strictly antagonistic relationship. In these studies, the authors proposed that the positive coupling between FPN and DMN was interpreted more appropriately as attention control working in the service of internal cognition. For instance Spreng et al. (2010, 2013) reported a positive correlation between FPN and DMN during retrieval of autobiographical memories, but not when participants engaged in a visuospatial task. This may be interpreted as attention control being oriented toward memory retrieval, biasing which internal signals (corresponding to memories) were to be retrieved and which were to be ignored.

These observations are consistent with the existence of a single attention control system, the FPN, which can be oriented to process internal or external sources of input (Figure 1B-ii). Moreover, these sources of input may correspond to other potential control systems - such as the DMN. Coincidently, during a visuospatial task, Spreng et al. $(2010,2013)$ found that the FPN was no longer coupled with the DMN, but was instead correlated positively with activities in frontal eye fields and inferior parietal sulci, which comprise the dorsal attention network (DAN), a specialized control system involved in visuospatial attention. From this perspective, internal cognition can lead to fluctuations of attention control by reorienting FPN away from systems controlling external inputs (e.g., interaction with DAN to process 
visuospatial information) and toward systems controlling internal inputs (e.g., interaction with DMN in the service of memory retrieval). One hypothesis that arises here is that such orienting of the FPN would be expected to suppress external signals in general (along with inappropriate internal signals such as false memories in the autobiographical retrieval example). Direct support for this idea has been reported: Mind wandering - a well-known example of an attention lapse-is associated with decreased processing of both attended and ignored external signals (Weissman et al., 2006; Smallwood et al., 2008; Barron et al., 2011; Kam et al., 2011), a phenomenon referred to recently as "perceptual decoupling" (Smallwood et al., 2007; Schooler et al., 2011).

\section{A LANDSCAPE OF ATTENTION CONTROL AND OUTSTANDING OUESTIONS}

The notion that multiple influences can modify the behavior of the FPN implies that attention control can take on multiple states that are determined by the context of its inputs and systemic influences, or more simply, by its system interactions. For instance, if we take the above examples of attention control inputs (internal/external) and activation (low/high arousal) and explore the product of their interactions along two axes, a landscape of attention control states emerges (Figure 2). Following the orientation axis, we see that attention control can be oriented internally or externally. We show no variability in orientation, acknowledging that it is categorical. Following the horizontal arousal axis, we see that attention control efficacy varies with arousal level with an optimum in the middle-reflecting the Yerkes-Dodson relationship exemplified by this system (Aston-Jones et al., 1999). Hence most efficacious attention states occur at the peak of this function, though the orientation can vary (e.g., focus can be directed internally such as when problem solving, or externally such as when reading a book), whereas in the extremes of the arousal axis, attention lapses occur. Scanning the resulting landscape, two important observations arise.

The first is that attention lapses can take on multiple flavors. In this analysis we observe four domains, produced by crossing arousal states with orientation of attention. If arousal is high, we predict that FPN will be excessively responsive to all stimuli and will therefore fail in discriminating between relevant and irrelevant inputs. If attention were oriented externally, this may be manifest as oversensitivity to external stimuli, whereas if attention were oriented internally, it might translate into racing thoughts (perhaps rumination). If however arousal is low, we predict that the FPN response will be sluggish, resulting in reduced responsivity to stimuli. Again discrimination between relevant and irrelevant stimuli would be compromised. In this case, if attention were oriented externally, we would expect behaviors to be driven by the most salient or most automatic responses ("bottom-up") since minimal control is applied to inputs. Similarly if attention were oriented internally, we would expect the presence of mind wandering, in which internal cognition drifts from one topic to another. This is also the state in which externally oriented attention would be vulnerable to drifting to internal content and, similarly, internal orientation could drift to external content. Note that in all four states the outward symptom would be poor attention to the task at hand, but for very different reasons.

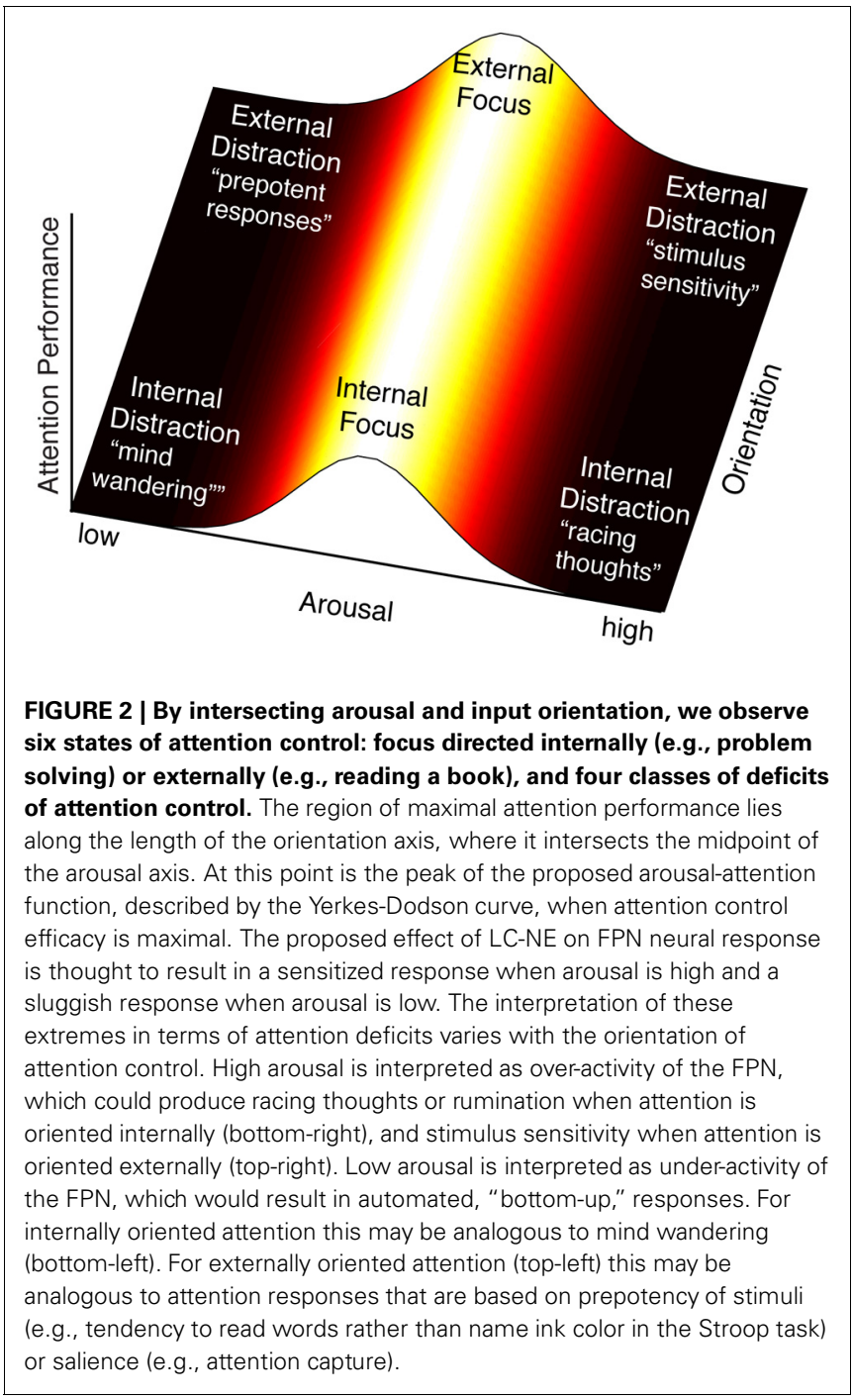

This perspective raises some questions regarding attention control mechanisms, especially with regard to internal cognition. The present synthesis implies that internal cognition is subject to the same rules of attention control that apply to external inputs: enhancement of relevant information and suppression of irrelevant information. Accordingly, distractions within internal cognition ought to be manifest much like those for external signals. As an example, consider the case where you attempt to meditate, but instead drift into thinking about work. Or imagine that you are trying to retrieve the name of a high-school friend (e.g., "Jenny"), but your memory keeps drifting to your colleague who has similar sounding last name (e.g., "Jensen"). In both cases, a potent unrelated thought captures your attention in the internal modality-much like when a loud sound captures your attention in the external modality. Therefore relevant and irrelevant signals may be defined for internal cognition much like external signals such as sights and sounds, and a correct response of the system would be for the FPN to suppress those irrelevant work thoughts, or the competing memory. 
What does it mean for FPN to suppress an internal thought? Can thoughts be conceived as isomorphic with levels of cortical activity, much like sounds and sights are isomorphic with levels of activity in auditory and visual cortices? If so, what are these cortical regions or networks that would be modulated? Would the structure of internal thought representations require an additional control system that interacts with the FPN? More generally, how would we measure lapses that occur within the internal modality? While certain aspects of attention control may be preserved between internal and external modalities, it is possible that asymmetries exist. Furthermore, while we describe a landscape of attentional states, we have not addressed how transitions occur between these states. How do the observed fluctuations in network activity and in behavioral performance relate to transitions in attentional states? For example, when FPN activity is low does this create a lower barrier for attention to wander or be captured? These are important questions that beg further investigation.

Our second, and related, observation is that current models of attention control are based largely on the study of externally oriented attention. Accordingly, investigations of attention control impairments are restricted largely to the upper half of Figure 2, more precisely to the upper left. Interestingly, while distractibility has been ascribed to a failure of the attention control network, the cause is not transparent. While it is certainly likely that in some disorders the FPN is impaired, in other instances an apparent dysfunction of FPN may be accounted for by low arousal decreasing activation of a normally functioning FPN. The implication of this proposition is that apparent dysfunctions of FPN may arise through multiple mechanisms. An interesting test case in this regard is ADHD. Key symptoms of this disorder have been impairments of working memory and response inhibition (Barkley, 1997; Tannock, 1998), leading to the inference that prefrontal cortex function, which subsumes core nodes of the FPN, is dysfunctional (Castellanos and Tannock, 2002; Arnsten, 2006; Casey and Riddle, 2012). Yet, the disorder also has been associated with an impairment of arousal, possibly due to an underlying noradrenergic disorder (van der Meere and Sergeant, 1988; McCracken, 1991; Biederman and Spencer, 1999).

\section{REFERENCES}

Andrews-Hanna, J. R. (2012). The brain's default network and its adaptive role in internal mentation. Neuroscientist 18, 251-270. doi: $10.1177 / 1073858411403316$

Andrews-Hanna, J. R., Reidler, J. S., Huang, C., and Buckner, R. L. (2010). Evidence for the default network's role in spontaneous cognition. J. Neurophysiol. 104, 322-335. doi: 10.1152/jn.00830. 2009

Arnsten, A. F. (2006). Fundamentals of attention-deficit/hyperactivity disorder: circuits and pathways. J. Clin. Psychiatry 67(Suppl 8), 7-12.

Aston-Jones, G., and Bloom, F. E. (1981). Activity of norepinephrinecontaining locus coeruleus neurons in behaving rats anticipates

Several questions arises: are the apparent attention control symptoms mediated, at least in part, by an underlying deficit in arousal and, therefore, the sustaining or engaging of attention control (Huang-Pollock and Nigg, 2003; Huang-Pollock et al., 2005; Castellanos et al., 2006; Friedman-Hill et al., 2010)? Are the fluctuations in attention control within an individual related to interactions of FPN with the LC-NE system? For instance, the fluctuations of attention control observed by Castellanos et al. (2005), more pronounced in children with ADHD, had a period of approximately $15 \mathrm{~s}$. Is this frequency correlated with the fluctuations of the LC-NE system in this group? Is the amplification of these fluctuations related to an aberration in the cellular properties of the neuromodulatory projections?

\section{CONCLUSION}

Our objective in this perspective is to highlight the significance of known fluctuations of attention control. We suggest that sources of these fluctuations consist of two categories, systemic and input, and that may they be thought of as interactions between FPN and other neural systems. We have presented a possible landscape of attention control that may result from the interactions of these systems. Recognizing that this demonstration is incomplete-inevitably other neuromodulators, other networks and associated system interactions are involved-we present this short perspective to highlight the increasing emphasis on and exciting research that has emerged in describing the brain in terms of network interactions. We believe that understanding of these interactions in the context of attention control fluctuations is imminent and will lead to an improved characterization of the dynamics of attention control and of its impairments.

\section{ACKNOWLEDGMENTS}

The authors would like to acknowledge the NIH for financial support: grant\# R33DA026109 and R21MH096329 (MSC). Agatha Lenartowicz is a fellow of the Third Generation Klingenstein Foundation. We would like to thank our reviewers for invaluable feedback on the manuscript and the ideas presented within.

Barron, E., Riby, L. M., Greer, J., and Smallwood, J. (2011). Absorbed in thought: the effect of mind wandering on the processing of relevant and irrelevant events. Psychol. Sci. 22, 596-601. doi: 10.1177/ 0956797611404083

Berridge, C. W., and Waterhouse, B. D. (2003). The locus coeruleusnoradrenergic system: modulation of behavioral state and statedependent cognitive processes. Brain Res. Brain Res. Rev. 42, 33-84. doi: 10.1016/S0165-0173 (03)00143-7

Biederman, J., and Spencer, T. (1999). Attention-deficit/hyperactivity disorder (ADHD) as a noradrenergic disorder. Biol. Psychiatry 46, 1234-1242. doi: 10.1016/S00063223(99)00192-4
Binder, J. R., Frost, J. A., Hammeke, T. A., Bellgowan, P. S. F., Rao, S. M., and Cox, R. W. (1999). Conceptual processing during the conscious resting state: a functional MRI study. J. Cogn. Neurosci. 11, 80-93. doi: 10.1162/089892999563265

Botvinick, M. M., Braver, T. S., Barch, D. M., Carter, C. S., and Cohen, J. D. (2001). Conflict monitoring and cognitive control. Psychol. Rev. 108, 624-652. doi: 10.1037/0033-295X. 108.3.624

Braver, T. S., and Cohen, J. D. (2000). "On the control of control: the role of dopamine in regulating prefrontal function and working memory," in Attention and Performance XVIII, eds S. Monsell and J. Driver (Cambridge, MA: MIT Press), 713-737. 
Briand, L. A., Gritton, H., Howe, W. M., Young, D. A., and Sarter, M. (2007). Modulators in concert for cognition: modulator interactions in the prefrontal cortex. Prog. Neurobiol. 83, 69-91. doi: 10.1016/j.pneurobio. 2007.06.007

Buckner, R. L., Andrews-Hanna, J. R., and Schacter, D. L. (2008). The brain's default network - Anatomy, function, and relevance to disease. Ann. N.Y. Acad. Sci. 1124, 1-38.

Capotosto, P., Babiloni, C., Romani, G. L., and Corbetta, M. (2009). Frontoparietal cortex controls spatial attention through modulation of anticipatory alpha rhythms. J. Neurosci. 29, 5863-5872. doi: 10.1523/JNEUROSCI.0539-09.2009

Casey, B. J., and Riddle, M. (2012). "Typical and atypical development of attention," in Cognitive Neuroscience of Attention, 2nd Edn., ed M. Posner (New York, NY: Guilford Press), 514.

Castellanos, F. X., Sonuga-Barke, E. J. S., Milham, M. P., and Tannock, R. (2006). Characterizing cognition in ADHD: beyond executive dysfunction. Trends Cogn. Sci. 10, 117-123. doi: 10.1016/j.tics.2006.01.011

Castellanos, F. X., Sonuga-Barke, E. J. S., Scheres, A., Di Martino, A., Hyde, C., and Walters, J. R. (2005). Varieties of attention-deficit/hyperactivity disorderrelated intra-individual variability. Biol. Psychiatry 57, 1416-1423. doi: 10.1016/j.biopsych.2004.12.005

Castellanos, F. X., and Tannock, R. (2002). Neuroscience of attention-deficit/hyperactivity disorder: the search for endophenotypes. Nat. Rev. Neurosci. 3, 617-628.

Christoff, K. (2012). Undirected thought: neural determinants and correlates. Brain Res. 1428, 51-59. doi: 10.1016/j.brainres.2011.09.060

Christoff, K., Gordon, A. M., Smallwood, J., Smith, R., and Schooler, J. W. (2009). Experience sampling during fMRI reveals default network and executive system contributions to mind wandering. Proc. Natl. Acad. Sci. U.S.A. 106, 8719-8724. doi: 10.1073/pnas. 0900234106

Corbetta, M., Patel, G., and Shulman, G. L. (2008). The reorienting system of the human brain: from environment to theory of mind. Neuron 58, 306-324. doi: 10.1016/j.neuron. 2008.04.017

Corbetta, M., and Shulman, G. L. (2002). Control of goal-directed and stimulus-driven attention in the brain. Nat. Rev. Neurosci. 3, 201-215. doi: 10.1038/nrn755
Coull, J. T. (1998). Neural correlates of attention and arousal: insights from electrophysiology, functional neuroimaging and psychopharmacology. Prog. Neurobiol. 55, 343-361. doi: 10.1016/S0301-0082(98)00011-2

Desimone, R., and Duncan, J. (1995) Neural mechanisms of selective visual-attention. Annu. Rev. Neurosci. 18, 193-222. doi: 10.1146/ annurev.ne.18.030195.001205

Dosenbach, N. U. F., Visscher, K. M., Palmer, E. D., Miezin, F. M., Wenger, K. K., Kang, H. S. C., et al. (2006). A core system for the implementation of task sets. Neuron 50, 799-812. doi: $\quad$ 10.1016/j.neuron.2006. 04.031

Foote, S. L., Bloom, F. E., and AstonJones, G. (1983). Nucleus locus ceruleus-new evidence of anatomical and physiological specificity. Physiol. Rev. 63, 844-914.

Foote, S. L., Freedman, R., and Oliver, A. P. (1975). Effects of putative neurotransmitters on neuronal-activity in monkey auditory-cortex. Brain Res. 86, 229-242. doi: 10.1016/00068993(75)90699-X

Foote, S. L., and Morrison, J. H. (1987). Extrathalamic modulation of cortical function. Annu. Rev. Neurosci. 10, 67-95. doi: 10.1146/annurev.ne. 10.030187.000435

Fox, M. D., Corbetta, M., Snyder, A. Z., Vincent, J. L., and Raichle, M. E. (2006). Spontaneous neuronal activity distinguishes human dorsal and ventral attention systems. Proc. Natl. Acad. Sci. U.S.A. 103, 10046-10051. doi: 10.1073/ pnas.0604187103

Fox, M. D., and Raichle, M. E. (2007). Spontaneous fluctuations in brain activity observed with functional magnetic resonance imaging. Nat. Rev. Neurosci. 8, 700-711. doi: $10.1038 / \mathrm{nrn} 2201$

Fox, M. D., Snyder, A. Z., Vincent, J. L., Corbetta, M., Van Essen, D. C., and Raichle, M. E. (2005). The human brain is intrinsically organized into dynamic, anticorrelated functional networks. Proc. Natl. Acad. Sci. U.S.A. 102, 9673-9678. doi: 10.1073/pnas.0504136102

Friedman-Hill, S. R., Wagman, M. R., Gex, S. E., Pine, D. S., Leibenluft, E., and Ungerleider, L. G. (2010). What does distractibility in ADHD reveal about mechanisms for top-down attentional control? Cognition 115, 93-103. doi: 10.1016/j.cognition. 2009.11.013

Gazzaley, A., Rissman, J., Cooney, J., Rutman, A., Seibert, T., Clapp, W., et al. (2007). Functional interactions between prefrontal and visual association cortex contribute to topdown modulation of visual processing. Cereb. Cortex 17, I125-I135. doi: $10.1093 /$ cercor/bhm113

Giambra, L. M. (1995). A laboratory method for investigating influences on switching attention to taskunrelated imagery and thought. Conscious. Cogn. 4, 1-21. doi: 10.1006/ccog.1995.1001

Gordon, A., Smith, R., Keramatian, K. Luus, B., Weinberg, A., Smallwood, J., et al. (2007). Mind-wandering, awareness, and task performance: an fMRI study. Can. J. Exp. Psychol. 61, 366

Gusnard, D. A., Akbudak, E., Shulman, G. L., and Raichle, M. E. (2001). Medial prefrontal cortex and selfreferential mental activity: relation to a default mode of brain function. Proc. Natl. Acad. Sci. U.S.A. 98, 4259-4264. doi: 10.1073/pnas. 071043098

Huang-Pollock, C. L., and Nigg, J. T. (2003). Searching for the attention deficit in attention deficit hyperactivity disorder: the case of visuospatial orienting. Clin. Psychol. Rev. 23 , 801-830. doi: 10.1016/S0272-7358 (03)00073-4

Huang-Pollock, C. L., Nigg, J. T., and Carr, T. H. (2005). Deficient attention is hard to find: applying the perceptual load model of selective attention to attention deficit hyperactivity disorder subtypes. J. Child Psychol. Psychiatry 46, 1211-1218. doi: $\quad 10.1111 /$ j.1469-7610.2005 00410.x

Johnson, S. C., Baxter, L. C., Wilder, L. S., Pipe, J. G., Heiserman, J. E., and Prigatano, G. P. (2002). Neural correlates of self-reflection. Brain 125, 1808-1814. doi: 10.1093/brain/ awf181

Kam, J. W. Y., Dao, E., Farley, J., Fitzpatrick, K., Smallwood, J., Schooler, J. W., et al. (2011). Slow fluctuations in attentional control of sensory cortex. J. Cogn. Neurosci. 23, 460-470. doi: 10.1162/jocn. 2010.21443

Leech, R., Braga, R., and Sharp, D. J. (2012). Echoes of the brain within the posterior cingulate cortex. J. Neurosci. 32, 215-222. doi: 10.1523/JNEUROSCI.3689-11. 2012

Mason, M. F., Norton, M. I., Van Horn, J. D., Wegner, D. M., Grafton, S. T., and Macrae, C. N. (2007) Wandering minds: the default network and stimulus-independent thought. Science 315, 393-395. doi: 10.1126/science. 1131295

Mason, S. T., and Iversen, S. D. (1978). Reward, attention and dorsal noradrenergic bundle. Brain Res. 150,
135-148. doi: 10.1016/0006-8993 (78)90658-3

Mazoyer, B., Zago, L., Mellet, E. Bricogne, S., Etard, O., Houde, O., et al. (2001). Cortical networks for working memory and executive functions sustain the conscious resting state in man. Brain Res. Bull. 54, 287-298. doi: 10.1016/S0361-9230 (00)00437-8

McCracken, J. T. (1991). A two-part model of stimulant action on attention-deficit hyperactivity disorder in children. J. Neuropsychiatry Clin. Neurosci. 3, 201-209.

McVay, J. C., and Kane, M. J. (2009). Conducting the train of thought: working memory capacity, goal neglect, and mind wandering in an executive-control task. J. Exp. Psychol. Learn. Mem. Cogn. 35, 196-204. doi: 10.1037/a0014104

McVay, J. C., and Kane, M.J. (2010). Does mind wandering reflect executive function or executive failure? Comment on Smallwood and Schooler (2006) and Watkins (2008). Psychol. Bull. 136, 188-197. doi: 10.1037/a0018298

Miller, E. K., and Cohen, J. D. (2001). An integrative theory of prefrontal cortex function. Annu. Rev. Neurosci. 24, 167-202. doi: 10.1146/ annurev.neuro.24.1.167

Monto, S., Palva, S., Voipio, J., and Palva, J. M. (2008). Very slow EEG fluctuations predict the dynamics of stimulus detection and oscillation amplitudes in humans. J. Neurosci. 28, 8268-8272. doi: 10.1523/ JNEUROSCI.1910-08.2008

Moore, R. Y., and Bloom, F. E. (1979). Central catecholamine neuron systems-anatomy and physiology of the norepinephrine and epinephrine systems. Annu. Rev. Neurosci. 2, 113-168. doi: 10.1146/ annurev.ne.02.030179.000553

Moruzzi, G., and Magoun, H. W. (1949). Brain stem reticular formation and activation of EEG. Electroencephalogr. Clin. Neurophysiol. 1, 455-473. doi: 10.1016/0013-4694(49)90219-9

Posner, M. I., and Dehane, S. (1994). Attentional networks. Trends Neural Sci. 17, 75-79. doi: 10.1016/01662236(94)90078-7

Posner, M. I., and Petersen, S. E. (1990). The attention system of the human brain. Annu. Rev. Neurosci. 13, 25-42. doi: 10.1146/annurev.ne. 13.030190.000325

Raichle, M. E. (2011). The restless brain. Brain Connect. 1, 3-12. doi: 10.1089/brain.2011.0019

Raichle, M. E., Macleod, A. M., Snyder, A. Z., Powers, W. J., Gusnard, D. A., and Shulman, G. L. (2001). 
A default mode of brain function. Proc. Natl. Acad. Sci. U.S.A. 98, 676-682. doi: 10.1073/pnas.98. 2.676

Rokem, A., Landau, A. N., Garg, D., Prinzmetal, W., and Silver, M. A. (2010). Cholinergic enhancement increases the effects of voluntary attention but does not affect involuntary attention. Neuropsychopharmacology 35 , 2538-2544. doi: 10.1038/npp. 2010.118

Roussel, B., Buguet, A., Bobillier, P., and Jouvet, M. (1967). [Locus ceruleus, paradoxal sleep, and cerebral noradrenaline]. C. R. Seances Soc. Biol. Fil. 161, 2537-2541.

Ruff, C. C., and Driver, J. (2006). Attentional preparation for a lateralized visual distractor: behavioral and fMRI evidence. J. Cogn. Neurosci. 18, 522-538. doi: 10.1162/ jocn.2006.18.4.522

Schooler, J. W., Smallwood, J., Christoff, K., Handy, T. C., Reichle, E. D., and Sayette, M. A. (2011). Meta-awareness, perceptual decoupling and the wandering mind. Trends Cogn. Sci. 15, 319-326.

Shulman, G. L., Fiez, J. A., Corbetta, M., Buckner, R. L., Miezin, F. M., Raichle, M. E., et al. (1997). Common blood flow changes across visual tasks.2. Decreases in cerebral cortex. J. Cogn. Neurosci. 9, 648-663. doi: 10.1162/jocn.1997.9. 5.648

Smallwood, J. (2012). Understanding unconstrained mental processes during waking thought: a cognitive neuroscience exploration of the wandering mind. Can. J. Exp. Psychol. 66, 316.

Smallwood, J., Beach, E., Schooler, J. W., and Handy, T. C. (2008). Going AWOL in the brain: mind wandering reduces cortical analysis of external events. J. Cogn. Neurosci. 20, 458-469. doi: 10.1162/ jocn.2008.20037

Smallwood, J., Brown, K., Baird, B., and Schooler, J. W. (2012). Cooperation between the default mode network and the frontal-parietal network in the production of an internal train of thought. Brain Res. 1428, 60-70. doi: 10.1016/j.brainres.2011.03.072

Smallwood, J., McSpadden, M., and Schooler, J. W. (2007). The lights are on but no one's home: metaawareness and the decoupling of attention when the mind wanders. Psychonom. Bull. Rev. 14, 527-533. doi: 10.3758/BF03194102

Smallwood, J., and Schooler, J. W. (2006). The restless mind. Psychol. Bull. 132, 946-958. doi: 10.1037/ 0033-2909.132.6.946

Spreng, R. N., Sepulcre, J., Turner, G. R., Stevens, W. D., and Schacter, D. L. (2013). Intrinsic architecture underlying the relations among the default, dorsal attention, and frontoparietal control networks of the human brain. J. Cogn. Neurosci. 25, 74-86. doi: 10.1162/jocn_a_00281

Spreng, R. N., Stevens, W. D., Chamberlain, J. P., Gilmore, A. W., and Schacter, D. L. (2010).
Default network activity, coupled with the frontoparietal control network, supports goal-directed cognition. Neuroimage 53, 303-317. doi: 10.1016/j.neuroimage.2010. 06.016

Sridharan, D., Levitin, D. J., and Menon, V. (2008). A critical role for the right fronto-insular cortex in switching between centralexecutive and default-mode networks. Proc. Natl. Acad. Sci. U.S.A. 105, 12569-12574. doi: 10.1073/ pnas.0800005105

Stawarczyk, D., Majerus, S., Maquet, P. and D'argembeau, A. (2011). Neural correlates of ongoing conscious experience: both task-unrelatedness and stimulus-independence are related to default network activity. PLoS ONE 6:e16997. doi: 10.1371/ journal.pone.0016997

Tannock, R. (1998). Attention deficit hyperactivity disorder: advances in cognitive, neurobiological, and genetic research. J. Child Psychol. Psychiatry 39, 65-99. doi: 10.1111/ 1469-7610.00304

van der Meere, J., and Sergeant, J. (1988). Focused attention in pervasively hyperactive children. J. Abnorm. Child Psychol. 16, 627-639. doi: 10.1007/BF00913474

Vincent, J. L., Kahn, I., Snyder, A. Z., Raichle, M. E., and Buckner, R. L. (2008). Evidence for a frontoparietal control system revealed by intrinsic functional connectivity. J. Neurophysiol. 100, 3328-3342. doi: $10.1152 /$ jn. 90355.2008
Weissman, D. H., Roberts, K. C., Visscher, K. M., and Woldorff, M. G. (2006). The neural bases of momentary lapses in attention. Nat. Neurosci. 9, 971-978. doi: 10.1038/ nn1727

Weissman, D. H., Warner, L. M., and Woldorff, M. G. (2009). Momentary reductions of attention permit greater processing of irrelevant stimuli. Neuroimage 48, 609-615. doi: 10.1016/j.neuroimage.2009. 06.081

Conflict of Interest Statement: The authors declare that the research was conducted in the absence of any commercial or financial relationships that could be construed as a potential conflict of interest.

Received: 01 May 2013; accepted: 02 July 2013; published online: 23 July 2013.

Citation: Lenartowicz A, Simpson GV and Cohen MS (2013) Perspective: causes and functional significance of temporal variations in attention control. Front. Hum. Neurosci. 7:381. doi: 10.3389/ fnhum.2013.00381

Copyright (C) 2013 Lenartowicz, Simpson and Cohen. This is an openaccess article distributed under the terms of the Creative Commons Attribution License, which permits use, distribution and reproduction in other forums, provided the original authors and source are credited and subject to any copyright notices concerning any third-party graphics etc. 